\title{
MULTIFACTORIAL MAPPING OF QTL FOR YIELD AND YIELD COMPONENT IN WHEAT (TRITICUM AESTIVUM) IN NORMAL AND DROUGHT CONDITIONS
}

\author{
HAMZA, H. ${ }^{1,2}-$ Asghari, A. ${ }^{3 *}-$ Mohammadi, S. A. ${ }^{4}$ - Sofalian, O. ${ }^{5}-$ MoHAMmadi, S. ${ }^{6}$ \\ ${ }^{1}$ University of Mohaghegh Ardabili, Ardabil, Iran \\ ${ }^{2}$ PNU Center of Mahabad, Mahabad, Iran (e-mail: Hamze_606@yahoo.com; \\ phone: +98-44-4233-5320; +98-914-444-3403) \\ ${ }^{3}$ Agronomy and Plant Breeding Department, Agriculture and Natural Resources Faculty, \\ University of Mohaghegh Ardabil, Ardabil, Iran \\ ${ }^{4}$ Department of Plant Breeding and Biotechnology, Faculty of Agriculture, University of Tabriz \\ Tabriz, Iran (e-mail: mohammadi@tabrizu.ac.ir; phone: +98-914-311-4335) \\ ${ }^{5}$ College of Agriculture Research, University of Mohaghegh Ardabil \\ Ardabil, Iran (e-mail: sofalian@uma.ac.ir; phone: +98-914-403-9186) \\ ${ }^{6}$ Seed and Plant Improvement Research Department, West Azerbaijan Agricultural and Natural \\ Resources Research Center, AREEO,Urmia,_Iran (e-mail: soleyman_45@yahoo.com) \\ *Corresponding author \\ e-mail: ali_asgharii@uma.ac.ir; phone: +98-914-304-2117 \\ (Received 19 $9^{\text {th }}$ Jul 2017; accepted $24^{\text {th }}$ Nov 2017)
}

\begin{abstract}
In order to mapping main and epistatic effects and environmental interactions of QTLs for yield and yield component in normal and water deficit conditions in wheat, A recombinant inbred lines population, comprising 148 lines derived from a cross between two winter wheat cultivars, 'YecoraRojo' and 'No. 49', was evaluated in two location in Iran (Miandoab and Mahabad) during 2014-2016. A linkage map including 177 microsatellite and 51 retrotransposon markers were used in this study. Quantitative trait loci (QTL) were determined for additive effects and additive $\times$ additive epistatic interactions using the QTL Cartographer 2.5 and QTL Network 2.0 software based on the CIM and mixed-linear method. Results showed in normal condition 3 QTL $\left(\mathrm{R}^{2}{ }_{\mathrm{A}}=5.0\right.$ to $\left.9.9 \%\right), 2$ QTL $\times$ environments $\left(\mathrm{R}^{2}{ }_{\mathrm{AE}}=5.81 \%\right), 10$ additive $\times$ additive epistatic effects $\left(\mathrm{R}_{\mathrm{AA}}{ }^{\mathrm{A}}=1.74\right.$ to $\left.7.80 \%\right)$ and 27 QTL $\times$ QTL $\times$ environmental interactions $\left(\mathrm{R}_{\mathrm{AAE}}^{2}=0.58\right.$ to 12.10$)$ were significant. In water deficit conditions, 3 QTLs $\left(\mathrm{R}_{\mathrm{A}}^{2}=5.0\right.$ to 10.94$), 1$ QTL $\times$ environmental interactions $\left(\mathrm{R}^{2}{ }_{\mathrm{AE}}=3.1 \%\right)$, 8 additive $\times$ additive inactions $\left(\mathrm{R}_{\mathrm{AA}}^{2}=0.88\right.$ to $\left.10.54 \%\right)$ and 20 QTL $\times$ QTL $\times$ environmental interactions $\left(\mathrm{R}_{\mathrm{AAE}}^{2}=3.46\right.$ to 11.26$)$ were identified. In two conditions 4 QTL funded for grain yield with $\mathrm{R}_{\mathrm{A}}^{2}$ value 5.0 to $10.96 \%$ which, 3 of them were located on A genome. Also, the largest number of QTLs for yield and yield component located on chromosome $3 \mathrm{~A}$ which can be used these chromosomes in genetic engineering. Also, most of the repeatedly detected QTL across environments were not significant.
\end{abstract}

Keywords: grain yield, epistatic QTL, main-effect QTL, microsatellite marker, wheat

\section{Introduction}

Bread wheat (Triticum aestivum L) is one of the world's most important food crops, providing $40 \%$ of the world's food. With increasing the number of population in the world, the global appeal for wheat will increase by $40 \%$ before 2020 . Therefore, a method to solve this problem is to breed more productive varieties of wheat (Dixon, 
2009; Wei et al., 2014). Hexaploid wheat $(2 n=6 x=42)$ has a large genome size of about $17300 \mathrm{Mb}$ (Hussain and Rivandi, 2007). Repetitive DNA elements make for approximately $90 \%$ and transposable elements make up $80 \%$ of wheat genome (Wanjugi et al., 2009).

Determining the number of controlling genes and them effect on qualitative traits such as yield and yield components are fundamental steps towards molecular breeding of crops (Cooper et al., 2009; Lapitan et al., 2009). Genetic studies under drought stress environments identified quantitative trait loci (QTL) for yield and yield component of wheat (Kirigwi et al., 2007; El-Feki, 2010; McIntyre et al., 2010; Pinto et al., 2010). QTL analysis establishes a link between continuous phenotypic variation and inheritance mechanisms resulting from genetic variation of single gene locations, and QTL identification makes the selection with the help of markers possible (Koroff et al., 2008; Emebiri et al., 2009). The grain yield of wheat and cereals in general, is a polygenic and highly complex trait that is influenced by environmental and genetic interactions at all stages of the plants growth (Slafer, 2003). QTL mapping has been increasingly utilized as a strategy to detect genomic regions important for grain yield and other genetically complex traits in cereal species (Cuthbert et al., 2008; Rebetzke et al., 2012). Therefore the discovery, understanding and eventual incorporation of genes and alleles that beneficially influence yield are major targets for breeding programs worldwide (Simmonds et al., 2014). Many chromosomal regions with minor effects have been detected in controlling yield, but repeatable QTL across environments and different backgrounds are rare.Therefore, concentrating on the exploration and utilization of genomic regions for traits related to drought tolerance may be a more feasible strategy than yield per se approaches. Previous studies have shown that different QTL was detected for grain yield in which are uniformly distributed across the entire genome and all 21 wheat chromosomes have been involved in controlling grain yield in wheat. Most of the QTL were detected on chromosome number of 4A, 3B and 2B (Zhang et al., 2009).

Additive effects and additive $\times$ additive epistatic effects are an essential factor affecting the phenotypic expression of complex trait genes and genetic variations in populations (Liao et al., 2001). Commonly, the detected additive $\times$ additive interactions contained all three types of epistatic effects, classified on the basis of whether the QTL involved exhibited their own main effects or not. These types were nominated to be epistatic between two additive loci, between an epistatic locus and an additive locus, or between epistatic loci only, which are equivalent to the terms of interactions between QTL, interactions between QTL and background loci, and interactions between complementary loci ( $\mathrm{Li}, 1998)$. Li et al. (2014) found thirteen significant QTL with additive effects for biomass, grain yield, and straw yield. They also reported of which six exhibited epistatic effects, eleven significant additive $\times$ additive interactions were detected, of which seven occurred between QTL showing epistatic effects only, two occurred between QTL showing epistatic effects and additive effects, and two occurred between QTL with additive effects. These QTL explained 1.20 to $10.87 \%$ of the total phenotypic variation. In study of Li et al. (2016) a total of 41 QTL with additive effects on different traits were mapped on most wheat chromosomes, excluding 1A, 2A, 3D, 4D, 6D, and 7B. Seven chromosome regions showed either tightly linked QTL or QTL with pleiotropic effects on two to four traits. Ten pairs of QTL showed additive $x$ additive effects (AA), four QTL were involved in additive $\times$ environment (AE) effects, and one was involved in AAE effects. 
Considering the fact that in previous studies QTL interactions with the environment, QTL $\times$ QTL and of QTL $\times$ QTL $\times$ Environment interaction over different years and different environmental conditions less studied, the present research and its results can be different from other similar studies. The objective of this study was mapping of QTLs for yield and yield component in normal and water deficit stress conditions and there main and epistatic effects and environmental interactions in wheat. The results will be of great significance for helping breeders to enhance the yield of wheat.

\section{Materials and methods}

\section{Plant materials}

Plant materials used in this experiment, include 148 bread wheat recombinant inbred lines derived from the cross between Yecora Rojo (America originated as a paternal line 149, high Yield, dwarf and early mature) and genotype No. 49 (the origin of Sistan and Baluchestan, Iran as female line, high altitude and late mature). Lines were produced at Riverside University and through of Center of Excellence Molecular Breeding, University of Tabriz was placed at the disposal of this research.

\section{Field evaluation}

Studied lines with parents were planted on research farms of Mahabad University and Miyandoab Agricultural Research Center in 2014-2015. The above mentioned regions are grouped into semi-arid areas of Iran. In both experiments used alpha lattice design with two replications under normal and water deficit conditions. Each plot consisted of two rows with $2.5 \mathrm{~m}$ long and the inter row and inter plant spacing's were 20 and $5 \mathrm{~cm}$, respectively. Irrigation in stress and non-stress conditions was done after $90 \mathrm{~mm}$ evaporation from class A pan, depending on the temperature and evapotranspiration until heading stage. In water deficit stress conditions, irrigation was stopped at heading stage, but in normal irrigation conditions was continued until the heading stage. Crop care was alike for all lines. At physiological maturity number of grains per spike, number of spike, thousand kernel weights, grain yield and harvest index for each plot were measured.

\section{QTL analysis}

For QTL analysis the existing linkage map including of 177 microsatellite and 51 retrotransposons markers were used. In this map, 202 markers belonged to 36 linkage groups with a length of $691.36 \mathrm{~cm}$ and 26 markers were not associated with any linkage groups (Roder et al., 1998; Roder et al., 1995). According to linkage maps provided for wheat, 34 linkage groups correspond with 19 chromosomes of 21 chromosomes. The average distance between adjacent markers on the map was 3.42 $\mathrm{cm}$. QTL analysis was performed by QTL network 2.0 and QTL Cartographer 2.5 software's through mixed-linear and composite Interval Mapping (CIM) methods. Given that the population of recombinant inbred lines is a permanent population, QTL $\times$ environment, QTL $\times$ QTL, and QTL $\times$ QTL $\times$ environment interactions were also examined. It should be noted in cases which QTLs detected by cartographer and not detected by QTL network, there were no interaction between QTL $\times$ environment and these effects were not recorded on the tables. 


\section{Results}

\section{Phenotypic performance of wheat RILs and parents}

The phenotypic variation among wheat RILs and the parents of studied traits, measured in two years and two locations in average of normal and drought conditions are summarized in Table 1 and Figures 1 to 4. Yecora Rojo and No. 49 differed significantly in the measured traits, that phenotypic values of No. 49 for grain yield and grain yield component being much higher than Yecora Rojo. Some RILs had more extreme values than the parents in all conditions, showing substantial transgressive segregation, although the average values of RILs for those traits were intermediate between the parental values. Furthermore, all traits showed considerable phenotypic variation and continuous distributions, indicating their quantitative nature. Based on the results presented in Table 1, both the Skewness and Kurtosis of all traits were less than 1.0, implying polygenic inheritance and suitability of the data for QTL analysis (Table 1).

Table 1. Phenotypic summary of yield and grain yield component for Yecora Rojo (P1), No. 49 (P2), and the wheat RILs at two years and two locations in average of normal and drought condition

\begin{tabular}{c|c|c|c|c}
\hline Parameters & Spike per $\mathbf{~ m}^{\mathbf{2}}$ & Number of grains per spike & Thousand kernel weight & Grain yield \\
\hline Yecora Rojo & 47.08 & 20.26 & 53.65 & 47.52 \\
No. 49 & 67.08 & 23.01 & 54.03 & 56.04 \\
RILs mean & 59.47 & 18.82 & 52.50 & 46.79 \\
Minimum & 45.50 & 15.05 & 42.85 & 29.87 \\
Maximum & 77.33 & 23.06 & 62.64 & 61.61 \\
Std. deviation & 6.43 & 1.655 & 3.76 & 6.72 \\
Skewness & .378 & .183 & .040 & -.054 \\
Kurtosis & -.362 & -.237 & -.574 & -.774 \\
\hline
\end{tabular}

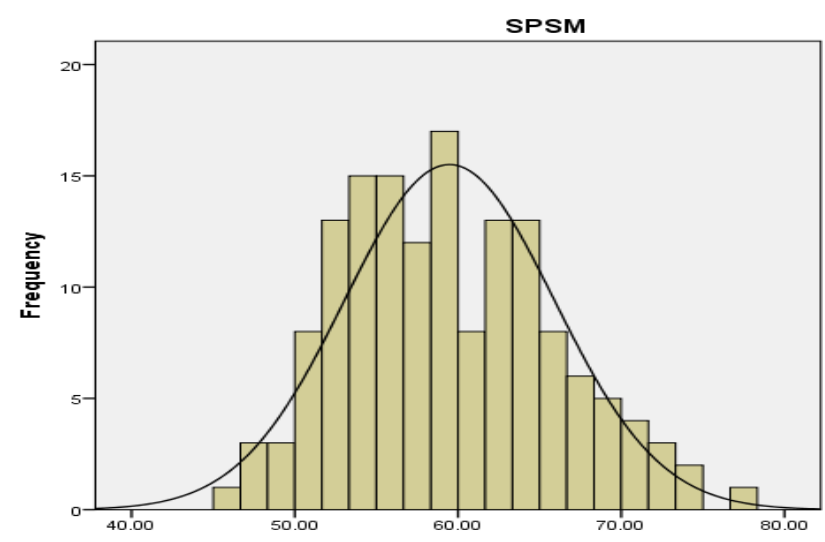

Figure 1. Frequency distributions of spike per square meter, two years conditions 


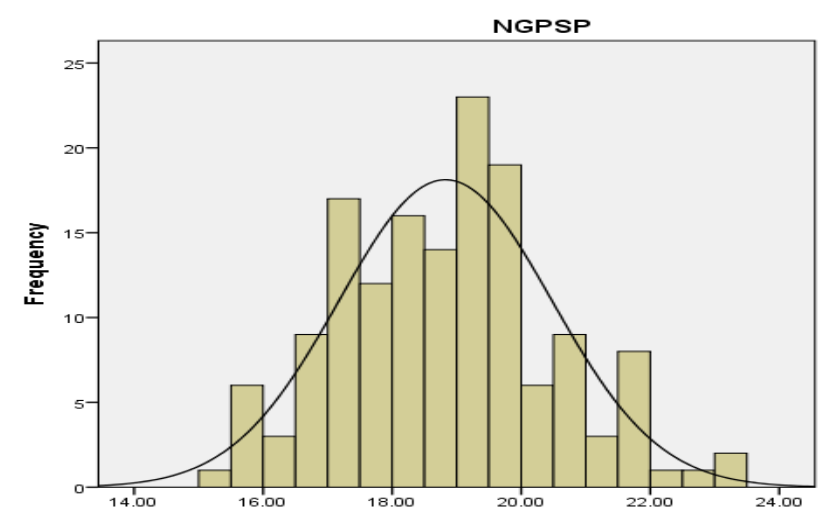

Figure 2. Frequency distributions of number of grains per two years, two locations and average of two conditions

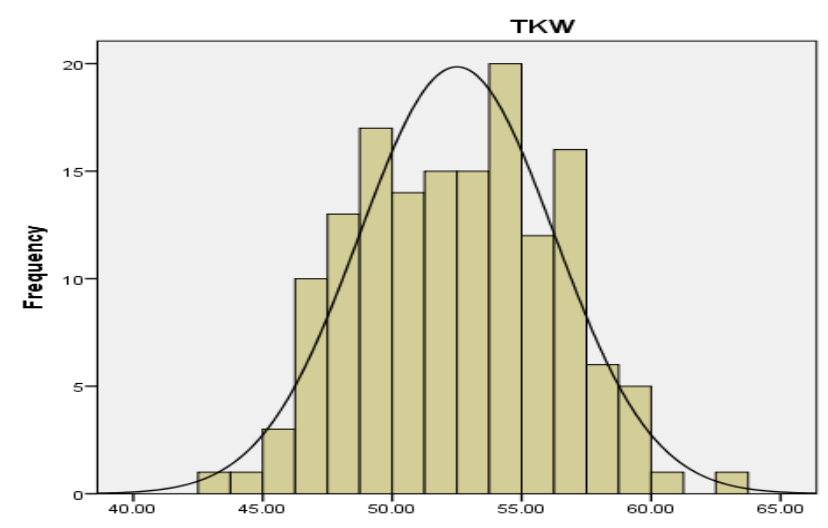

Figure 3. Frequency distributions of thousand kernel weight in two years, two locations and average of two conditions

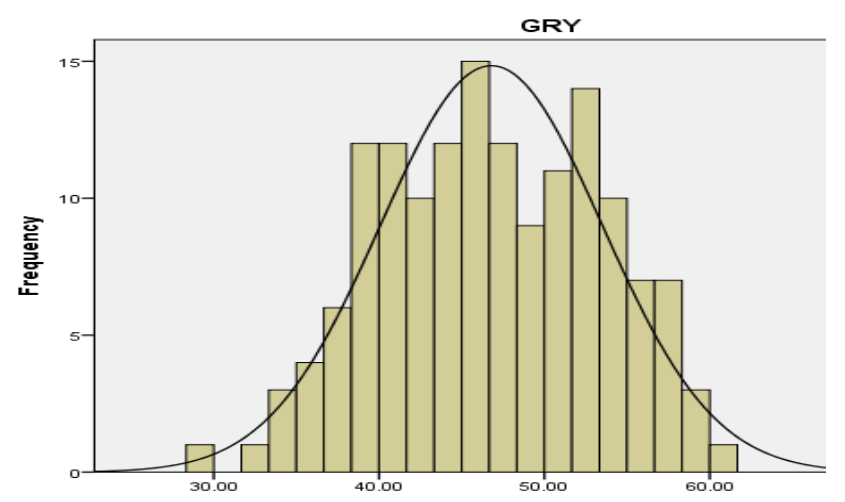

Figure 4. Frequency distributions of grain yield in two years, two locations and average of two conditions

\section{QTL mapping}

The results of QTL analysis are summarized in Tables 2, 3, and 4. In this research for four traits under study across both years and both locations under normal conditions, 3 QTLs $\left(\mathrm{R}_{\mathrm{A}}^{2}=5.0\right.$ to $\left.9.9 \%\right), 2$ QTL $\times$ environments $\left(\mathrm{R}_{\mathrm{AE}}^{2}=5.81 \%\right), 10$ additive $\times$ 
additive epistatic effects $\left(\mathrm{R}^{2}{ }_{\mathrm{AA}}=1.74\right.$ to $\left.7.80 \%\right)$ and 27 QTL $\times$ QTL $\times$ environment interactions $\left(\mathrm{R}_{\text {AAE }}^{2}=0.58\right.$ to 12.10$)$ were significant. Under water deficit conditions, 3 QTLs $\left(\mathrm{R}_{\mathrm{A}}^{2}=5.0\right.$ to 10.94$), 1 \mathrm{QTL} \times$ environmental interaction $\left(\mathrm{R}_{\mathrm{AE}}^{2}=3.1 \%\right), 8$ additive $\times$ additive inactions $\left(\mathrm{R}^{2}{ }_{\mathrm{AA}}=0.88\right.$ to $\left.10.54 \%\right)$ and 20 QTL $\times$ QTL $\times$ environment interactions $\left(\mathrm{R}_{\mathrm{AAE}}^{2}=3.46\right.$ to 11.26$)$ were identified.

Table 2. Detected QTL and QTL $\times$ environment interactions for studied traits in a RIL population of wheat obtained from Yecora Rojo $\times$ No. 49 at two years and two locations in normal and water deficit condition

\begin{tabular}{|c|c|c|c|c|c|c|c|c|c|c|c|}
\hline Trait & Chr. & QTL & Marker interval & $\begin{array}{c}\text { Position } \\
\text { (cm) }\end{array}$ & $\mathbf{A}$ & $\mathbf{R}_{b}^{2} \%$ & $\mathbf{A E _ { 1 }}$ & $\mathbf{A E _ { 2 }}$ & $\mathbf{A} \mathbf{E}_{3}$ & $\mathbf{A E}_{4}$ & $\mathbf{R}_{\mathrm{AE}}^{2}$ \\
\hline \multirow{2}{*}{$\begin{array}{l}\text { Spike per } \mathrm{m}^{2} \\
\quad \text { (normal) }\end{array}$} & & & $\begin{array}{c}\text { Wms566- } \\
\text { '5LTR.2/Sukkula.380 }\end{array}$ & 2.06 & -1.72 & 5.0 & - & - & - & - & - \\
\hline & $2 \mathrm{~A}$ & QSPSM2A-N & Gwm35- 'Gwm296 & 7.5 & -1.93 & $\begin{array}{c}6.0 \\
11 \\
\end{array}$ & - & - & - & - & - \\
\hline $\begin{array}{l}\text { Grain yield } \\
\text { (normal) }\end{array}$ & $7 \mathrm{~A}$ & QGY7A-N & 'Cfa2123- 'Gwm282 & 53.6 & -1.3963 & 9.9 & - & -2.80 & 2.56 & - & 5.81 \\
\hline \multirow{3}{*}{$\begin{array}{c}\text { Grain yield } \\
\text { (water deficit) }\end{array}$} & $3 \mathrm{~A}$ & QGY3A-S & $\begin{array}{c}\text { 5LTR.2/ISSR5.530- } \\
\text { 'Gwm66.2 }\end{array}$ & 582.2 & 5.11 & 10.94 & - & - & - & - & 0.14 \\
\hline & $5 \mathrm{~A}$ & QGY5A-S & 'Barc319- 'Cfa2141 & 8.0 & 1.7646 & 9.82 & - & 1.34 & - & - & 3.1 \\
\hline & $2 \mathrm{D}$ & QGY2D-S & Wms102- 'Wmc18 & 0 & 1.64 & 5 & - & - & & - & - \\
\hline
\end{tabular}

A: Additive effect, A positive value indicates that the allele from No. 49 increases the trait value; A negative value indicates that the allele from Yecora Rojo increases the trait value. b: Proportion of the phenotypic variation explained by the QTL. Ae: Additive $\times$ environmental effects. $\mathrm{R}_{\mathrm{AE}}^{2}$ : Proportion of the phenotypic variation explained by additive $\times$ environment effect

Table 3. Additive $\times$ additive epistatic $Q T L$ and $Q T L \times Q T L \times$ environment interactions for studied traits in two years and two locations at normal condition

\begin{tabular}{|c|c|c|c|c|c|c|c|c|c|c|c|c|c|}
\hline 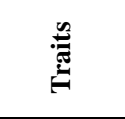 & రㄹㄹ & 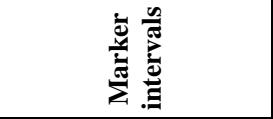 & 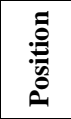 & $\vec{E}$ & 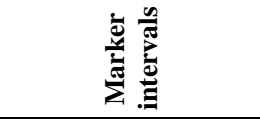 & 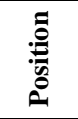 & 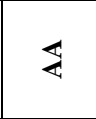 & $\begin{array}{l}a^{2} \\
\approx \\
\simeq\end{array}$ & $\sum_{4}^{-1}$ & $\sum_{4}^{9}$ & $\frac{9}{4}$ & $\sum_{4}^{+}$ & $\approx$ \\
\hline \multirow{2}{*}{$\begin{array}{l}\text { Spike per } \\
\mathrm{m}^{2}\end{array}$} & 6B & 'Barc178-'Gwm219 & $\underline{109.2}$ & $3 \mathrm{~A}$ & $\begin{array}{c}\text { Sukkula/ISSR10.600- } \\
\text { 'Sukkula/ISSR7.550 }\end{array}$ & 266.9 & 0.7092 & 1.8 & -3.84 & -4.99 & 5.12 & 3.80 & 12.10 \\
\hline & $4 \mathrm{~A}$ & 'Wmc468-'Barc170 & 0.0 & $7 \mathrm{~A}$ & 'Gwm276-'Cfa2123 & 35.5 & 0.5394 & $\begin{array}{l}2.2 \\
4.0\end{array}$ & -3.44 & -3.28 & 3.74 & 3.14 & $\begin{array}{l}11.18 \\
23.28\end{array}$ \\
\hline \multirow{4}{*}{$\begin{array}{l}\text { Thousand } \\
\text { kernel } \\
\text { weight }\end{array}$} & $5 \mathrm{~A}$ & 'Barc186-'Barc117 & 42.1 & $3 \mathrm{~A}$ & $\begin{array}{c}\text { 'Wms566- } \\
\text { '5LTR.2/Sukkula.380 }\end{array}$ & 56.2 & 1.12 & 3.8 & 1.52 & - & -1.58 & - & 8.42 \\
\hline & $5 \mathrm{~A}$ & 'Gwm617-'Wmc327 & 425.2 & 31 & $\begin{array}{c}\text { 'Wmc336- } \\
\text { 'LTR6150/ISSR3.500 }\end{array}$ & 25.2 & 1.52 & 4.42 & 1.95 & 2.50 & -1.98 & -2.41 & 10.18 \\
\hline & $3 \mathrm{~A}$ & $\begin{array}{l}\text { 'LTR6150/ISSR10.260- } \\
\text { '5LTR.2/ISSR5.530 }\end{array}$ & 523.2 & $2 \mathrm{~A}$ & 'Wms122-'Wmc296 & 17.9 & -4.89 & 1.74 & - & - & - & - & 0.58 \\
\hline & & & & & & & & 20.96 & & & & & 19.18 \\
\hline \multirow{5}{*}{$\begin{array}{l}\text { Grain } \\
\text { yield }\end{array}$} & $5 \mathrm{~A}$ & ' Gwm129-'Barc1 & 96.2 & $6 \mathrm{D}$ & 'Barc54-'Gwm325 & 0.0 & -2.2463 & 4.14 & -3.08 & -3.21 & 3.69 & 2.74 & 9.30 \\
\hline & $5 \mathrm{~A}$ & $\begin{array}{l}\text { LTR6149/Nikita.740- } \\
\text { 'Barc330 }\end{array}$ & 354.2 & $6 \mathrm{~A}$ & $\begin{array}{c}\text { 'Gwm459- } \\
\text { 'Sukkula/Nikita.450 }\end{array}$ & 5.3 & -2.3903 & 4.86 & - & - & - & 3.10 & 6.86 \\
\hline & $5 \mathrm{~A}$ & ' Barc330-'Gwm617 & 403.7 & 31 & $\begin{array}{c}\text { 'Wmc336- } \\
\text { 'LTR6150/ISSR3.500 }\end{array}$ & 23.2 & 5.3206 & 7.80 & 5.96 & 6.41 & -5.59 & -6.49 & 10.9 \\
\hline & 6B & 'Wms88-'Barc24 & 64.7 & 1B & $\begin{array}{l}\text { Sukkula/ISSR7.230- } \\
\text { 'LTR6149/ISSR2.180 }\end{array}$ & 3.7 & -3.5644 & 5.94 & -2.66 & - & - & 3.19 & 4.32 \\
\hline & $2 \mathrm{~A}$ & 'Wmc296-'Wms339 & 19.6 & $2 \mathrm{~A}$ & ' Gwm35-'Gwm296 & 1.0 & -3.4287 & $\left|\begin{array}{c}7.0 \\
29.68\end{array}\right|$ & -2.51 & - & - & 2.70 & $\begin{array}{l}5.18 \\
36.38\end{array}$ \\
\hline
\end{tabular}


Table 4. Additive $x$ additive epistatic QTL and $Q T L \times Q T L \times$ environment interactions for studied traits in two years and two locations at water deficit condition

\begin{tabular}{|c|c|c|c|c|c|c|c|c|c|c|c|c|c|}
\hline$\stackrel{\mathscr{E}}{\pi}$ & 苞 & 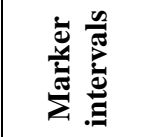 & : & 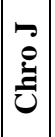 & 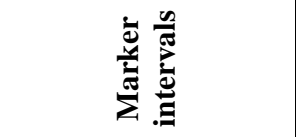 & : & $\mathbb{4}$ & $\begin{array}{l}\tilde{a}^{2} \\
\approx\end{array}$ & $\sum_{i}^{-1}$ & 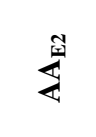 & $\sum_{4}^{3}$ & $\sum^{+}$ & $\approx$ \\
\hline$\underset{\mathrm{m}^{2}}{\text { Spike per }}$ & $2 B$ & 'Wms148- & 1.0 & $7 \mathrm{~B}$ & $\begin{array}{c}\text { 'Wms297- } \\
\text { 'Sukkula/Nikita.520 }\end{array}$ & 72.8 & -0.6881 & 0.88 & -2.211 & -2.310 & 2.474 & 2.04 & 11.26 \\
\hline \multirow{4}{*}{$\begin{array}{c}\text { Thousand } \\
\text { kernel } \\
\text { weight }\end{array}$} & $6 \mathrm{~B}$ & $\frac{\text { 'Wms88- }}{\text { 'Barc24 }}$ & 61.7 & 31 & $\begin{array}{c}\text { 'LTR6149/ISSR2.260- } \\
\text { 'Psp2999 }\end{array}$ & 5.0 & -1.5848 & 9.1 & - & - & - & - & 2.84 \\
\hline & $3 \mathrm{~A}$ & $\frac{\text { 'Barc45- }}{\text { 'Gwm2 }}$ & 0.0 & $5 \mathrm{~B}$ & 'Gwm499-'Gwm371 & 6.1 & -0.7424 & 2.28 & - & - & - & - & 3.46 \\
\hline & $6 \mathrm{D}$ & 'Barc54- & 1.0 & $2 \mathrm{~A}$ & 'Wms47-'Wmc198 & 0.0 & 0.5372 & 10.54 & 1.75 & 2.031 & -1.601 & -2.18 & 10.56 \\
\hline & & & & & & & & 21.92 & & & & & 17.54 \\
\hline \multirow{3}{*}{$\begin{array}{l}\text { Grain } \\
\text { yield }\end{array}$} & $5 \mathrm{~A}$ & $\begin{array}{l}\text { 'Gwm443- } \\
\text { 'Wms154 }\end{array}$ & 6.0 & $5 \mathrm{~A}$ & 'Barc180-'Gwm129 & 84.6 & 2.8509 & 6.76 & - & - & -2.201 & & 5.82 \\
\hline & $7 \mathrm{~B}$ & $\begin{array}{l}\text { 'Wms400- } \\
\text { 'Wms46 }\end{array}$ & 23.8 & $7 \mathrm{~B}$ & $\begin{array}{c}\text { 'Wms297- } \\
\text { 'Sukkula/Nikita.520 }\end{array}$ & 79.8 & 20.395 & 4.0 & 2.77 & 3.22 & -3.077 & -2.970 & 4.0 \\
\hline & & & & & & & & 10.76 & & & & & 9.82 \\
\hline
\end{tabular}

AA: Additive $\mathrm{x}$ additive effect, a positive value indicates that the effect of the parents' effect is larger than the recombinant effect, and a negative value means that the recombinant effect is larger than the parents' effect. b: Proportion of the phenotypic variation explained by additive $\mathrm{x}$ additive QTL. AAe: Additive $\mathrm{x}$ additive $\times$ environment effects. $\mathrm{R}_{\mathrm{AAE}}^{2}$ : Proportion of the phenotypic variation explained by additive $\mathrm{x}$ additive $\times$ environmental effects

\section{Spike per square meter}

In normal condition, two QTLs on chromosomes 3A and 2A were detected for spike per square meter (Table 2). These QTLs were linked with markers of Wms566'5LTR.2/Sukkula.380 and Gwm35- 'Gwm296 and in distance of 2.06 and $7.50 \mathrm{~cm}$. The amounts of additive value of these QTLs were -1.72 and -1.93 and explained $11.0 \%$ of total phenotypic variation. Two QTLs (QSPSM3A- N and QSPSM2A- N) were contributed by No.49 parent alleles. Also, in normal condition two pairs of significant additive $\times$ additive epistatic effects were observed for spike per square meter (Table 3 ). These interactions were existed between chromosomes of $3 \mathrm{~A} \times 6 \mathrm{~B}$ and $4 \mathrm{~A} \times 7 \mathrm{~A}$, which showed additive $\times$ additive values of 0.7092 and 0.5394 , respectively and justified $4.0 \%$ of total phenotypic variation. It should be noted that these epistatic (QSSM3A-N $\times$ QSSM6B-N and QSSM7A-N $\times$ QSSM7A-N) interactions acted by increasing the values of the parents types. In normal conditions, the effects of QTL $\times$ QTL were significant in four environments which accounted for $23.28 \%$ of the phenotypic variation $\left(\mathrm{R}_{\mathrm{AAE}}^{2}=23.28 \%\right)$.

In water deficit condition, one pair significant epistasis interaction (additive $\times$ additive) of QTL between chromosomes $7 \mathrm{~B} \times 2 \mathrm{~B}$ was detected (Table 4 ), which had additive $\times$ additive and $\mathrm{R}_{\text {AA }}^{2}$ value of 0.6881 and $0.88 \%$, respectively. This QTL acted by increasing the values of the parent's types. In additions, the effects of epistasis interaction between chromosomes (QSSM7B-S $\times$ QSSM2B-S) were significant in all environments with $\mathrm{R}_{\mathrm{AAE}}^{2}$ of $11.26 \%$. It should be noted there were no common QTL and epistasis effects in both conditions. In normal condition phenotypic variation explained by additive QTL effect was more than QTL $\times$ QTL epistasis effect, so can be said additive QTL effect played a more important role in controlling spike per square 
meter. Also, in both conditions the amount of epistatic interactions were small compared to the QTL $\times$ QTL $\times$ environmental effects, indicating that these epistatic pairs were highly sensitive to environments in the control spike per square meter.

\section{Thousand kernel weight}

In normal condition, three significant additive $\times$ additive epistasis effects between chromosomes of $3 \mathrm{~A} \times 5 \mathrm{~A}, 31 \times 5 \mathrm{~A}$ and $2 \mathrm{~A} \times 3 \mathrm{~A}$ were found for thousand kernel weight (Table 3). Amounts of additive $\times$ additive values for these effects were 1.12, 1.52 and 4.89 , respectively and these epistatic effects controlled $20.96 \%$ of phenotypic variation. Two interactions (QTKW3A-N $\times$ QTKW5A-N and QTKW31-N $\times$ QTKW5A-N) acted to increase the values of the parental types, and the others (QTKW2A-N $\times$ QTKW3A$\mathrm{N}$ ) acted in the opposite direction, that is, recombinant effects were larger than parental effects. Also, in this condition six QTL $\times$ QTL $\times$ environmental interactions were significant which $19.18 \%$ of phenotypic variations were explained by these interactions.

In water deficit condition, three pairs of additive $\times$ additive epistasis were detected between chromosomes $31 \times 6 \mathrm{~B}, 5 \mathrm{~B} \times 3 \mathrm{~A}$ and $\times 6 \mathrm{D} \times 2 \mathrm{~A}$, with additive $\times$ additive value of $-1.5848,-0.7424$ and 0.5372 (Table 4). The epistasis of QTKW6D-S $\times$ QTKW2A-S acted in favor of the parental type and accounting for $10.54 \%$ of the phenotypic variance. The other two interactions of QTKW31-S × QTKW6B-S and QTKW5B-S $\times$ QTKW3A-S, explained $11.38 \%$ of the phenotypic variation together. In this research additive $\times$ additive epistasis of QTKW6D-S $\times$ QTKW2A was significant in all environments and these interactions justified $10.56 \%$ of phenotypic variation.

In our research there were no common epistasis effects observed in both conditions for thousand kernel weight. In addition phenotypic variation explained by additive $x$ additive effect in both conditions exceeded than QTL $\times$ QTL $\times$ environmental effects, so can be said additive $\times$ additive effects are less influenced by the environment.

\section{Grain yield}

In normal condition only one QTL was detected on chromosome 7A for grain yield. This QTL (QGY7A-N) was linked with markers of Cfa2123- Gwm282, positioned within a $53.6 \mathrm{~cm}$, by $\mathrm{R}^{2}$ value of $9.9 \%$ and additive effects value of -1.3963 (Table 1), Favorable alleles were contributed at this QTL by Yecora Rojo parent. Also, in this condition two significant interaction effects between QTL $\times$ environments with $\mathrm{R}_{\mathrm{AE}}^{2}$ of 5.81 were detected. Also five pairs of significant additive $\times$ additive epistatic effect between chromosomes $5 \mathrm{~A} \times 6 \mathrm{D}, 5 \mathrm{~A} \times 6 \mathrm{~A}, 5 \mathrm{~A} \times 31,6 \mathrm{~B} \times 1 \mathrm{~B}$ and $2 \mathrm{~A} \times 2 \mathrm{~A}$ were identified. These epistatic effects evidenced additive $\times$ additive value of -2.2463 , $2.3903,5.3206,-3.5644$ and -3.4287 , respectively and explained $29.68 \%$ of the total phenotypic variance. The QTL pair of QGY31-N $\times$ QGY5A-N acted in favor of the parental types and effects of QGY6D-N $\times$ QGY5A-N, QGY6A- N $\times$ QGY5A-N, QGY1B- N $\times$ QGY6B-N and QGY2A- N $\times$ QGY2A-N acted to increase the values of the recombinant types. It should be noted that 13 significant interactions between QTL $\times$ QTL $\times$ environments which were detected for grain yield had $\mathrm{R}^{2}$ AA values ranging from 4.32 to $10.9 \%$ (Table 2).

Under water deficit condition, three QTLs on chromosomes 3A, 5B and 2D were detected for grain yield (Table 2). These QTL were linked with markers of 5LTR.2/ISSR5.530- 'Gwm66.2, 'Barc319- 'Cfa2141 and Wms102- 'Wmc18 and in distance of 582.2, 8 and $0 \mathrm{~cm}$. Amounts of additive values of these QTLs were 5.11, 
1.7646 and 1.640 and explained $25.76 \%$ of total phenotypic variation. All three QTLs (QGY3A-S, QGY5B-S and QGY2D- S) had positive effects on grain yield and were contributed by No.49 parent alleles. Out of these, one significant interaction between QTL (QGY5A-S) $\times$ environments with $\mathrm{R}_{\mathrm{AE}}^{2}$ values of $3.1 \%$ was detected for grain yield. Furthermore, two additive $\times$ additive epistatic effects were common in water deficit condition for grain yield (Table 3). These epistatic effects were located between chromosomes $5 \mathrm{~A} \times 5 \mathrm{~A}$ and $7 \mathrm{~B} \times 7 \mathrm{~B}$ with additive value of 2.8509 and 2.0395 , respectively and justified $10.76 \%$ of total phenotypic variation. These effects acted by increasing the values of the parental types. It should be noted that in water deficit condition five QTL $\times$ QTL $\times$ environmental interactions with $\mathrm{R}_{\text {AAE }}^{2}$ from 4.0 to $5.82 \%$ were identified. In all conditions, additive QTLs effects were more than additive $\times$ environmental effects which indicated additive QTLs are less influenced by the environment. In additions, in normal condition phenotypic variation explained by additive $\times$ additive epistatic effects were larger than additive QTLs effects. Thus, epistatic QTLs were more important than additive QTLs for grain yields, but in water deficit condition additive QTLs were more important than epistatic QTLs. Furthermore, in normal condition additive $\times$ additive epistatic effect was influenced by the

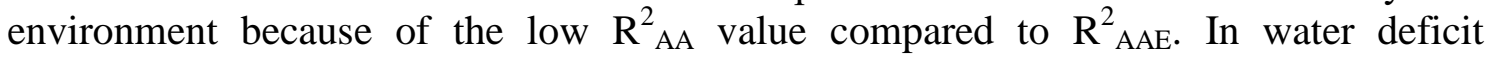
condition, these interactions less affected by the environmental effect compared with other conditions.

\section{Discussion}

QTLs for Spike per square meter and grain yield were detected on chromosomes 3A, 2A, 7A, 5A and 2D in two years and two locations in normal and water deficit conditions in the present study. Many QTL affecting yield have been reported on all chromosomes, with the exceptions of chromosomes 3D and 5D, in previous studies, and no significant gene by environment interactions were examined (Huang et al., 2006; Cuthbert et al., 2008; McIntyre et al., 2010). The significant QTLs simultaneously identified for spike per square meter and grain yield in the current study were located on chromosomes $3 \mathrm{~A}$. In fact, chromosomes $3 \mathrm{~A}$ are known to carry a number of major genes affecting spike per square meter and grain yield (Huang et al., 2006). Therefore, the QTL on 3A should be considered to increase wheat biomass, grain, and straw in wheat molecular breeding. Furthermore three significant interactions between QTL $\times$ environments were detected for grain yield in normal and water deficit condition. In all conditions additive QTL effects were more than additive $\times$ environment effects which indicated additive QTL are not influenced by the environmental effects. Marza et al. (2006) and Quarrie et al. (2005) discovered that a number of major genes affecting yield productivity were located on chromosome 5AL. Cuthbert et al. (2008) showed twograin yield QTL clusters on chromosomes 7A and 7B around the Xwmc273 locus. We detected a QTL (QGY7A- N) close to 'Cfa2123- 'Gwm282 on 7A with significant effects on grain yield. Unfortunately, however, we failed to detect any QTL on chromosome 7B. On chromosome 2D, a QTL that increased grain yield was detected using $402 \mathrm{DH}$ lines from the spring wheat cross Superb (high yielding)/BW278 (low yielding) by Cuthbert et al. (2008). The QTL on 2D affecting GY was also identified in our study. Zhang et al. (2009) and Li et al. (2014) also detected a QTL with significant effects on GY on chromosome 2D. In this study, no QTL for number of grains per spike, thousand kernel weights was observed in both conditions. The reason is probably 
the effect of a large number of QTLs with low effects in control of the mentioned traits (Tanksley, 1993) or influence of environmental effect on quantitative traits (George et al., 2003). Additive effects and additive $\times$ additive epistatic effects are an important factor affecting the phenotypic expression of complex trait genes and genetic variations in populations (Liao et al., 2001). Generally, the additive $\times$ additive interactions detected included all three types of epistatic effects, classified on the basis of whether the QTL involved exhibited their own main effects or not. In the present study, a total of 16 significant additive $\times$ additive interactions were detected for spike per square meter, thousand kernel weight, grain yield in two years and two locations in normal and water deficit conditions using a RIL population. Except additive $\times$ additive epistatic effects of QTKW7B-N $\times$ QTKW7B-2B-N under normal conditions, QTKW 6B-S $\times$ QTKW31-S and QTKW3A-S $\times$ QTKW 5B-S under water deficit condition for thousand kernel weight, all of the identified epistatic effects showed a significant interaction with the environment. Furthermore, in normal condition additive $\times$ additive epistatic effect was influenced by the environment but in water deficit condition, these interactions less affected by the environmental effect. Overall, the detection of additive and additive $\mathrm{x}$ additive effects of a QTL interfered with each other, indicating that the detection of QTL might vary greatly depending on their interactions with other loci in complex traits (Zhuang et al., 2002). Li et al. (2014) found 8 main QTLs, 3 QTL $\times$ environments interactions, 3 additive $\times$ additive epistatic effects and 2 QTL $\times$ QTL $\times$ environments interactions for grain yield. Zhang et al. (2014) located 17 QTLs on 14 chromosomal regions) $1 \mathrm{~A}-1,1 \mathrm{~B}-1,2 \mathrm{~B}-1,2 \mathrm{~B}-2$, 2D, 3B-1, 3B-2, 4B, 5A-1, 5B-2, 6B-2, 7A-4, 7A-5 and 7B-1 which were associated with grain yield. Furthermore, they identified 13 QTL $\times$ environments, five QTL $\times$ QTL interactions and nine QTL $\times$ QTL $\times$ Environment for grain yield. Wu et al. (2012) found 6 main QTLs, 2 QTL $\times$ environments interactions, 6 additive $\times$ additive epistatic effects and 5 QTL $\times$ QTL $\times$ environments interactions in wheat DH lines. In the study of Zhang et al. (2016) 10 QTLs were detected on chromosome 1D, 3A, 6B, 6D, 2A, 2B, 2D,5D, 6A-1 and 6A-2 in the five environments which accounting for $5.65-18.62 \%$ of the phenotypic variation for Spike per square meter. Wu et al. (2012), reported 13 main QTLs, 10 QTL $\times$ environments interactions, 17 additive $\times$ additive epistatic effects and 2 QTL $\times$ QTL $\times$ environmental interactions for thousand kernel weight at multiple rain-fed environments. In normal, water deficit and average of two conditions, additive QTL, QTL $\times$ environments, additive $\times$ additive epistatic effects by and QTL $\times$ QTL $\times$ environment interactions justify 68.22, 68.32 and 94 percent of total grain yield phenotypic variation. It can be concluded that interaction effects such as QTL $\times$ E, QTL $\times$ QTL and QTL $\times$ QTL $\times$ E play a more significant role in comparison with the main effects of additive QTL in control of grain yield. From total markers, 50 markers showed tight linkage to the QTLs which related to grain yield, and most of them might be useful for marker-assisted selection. In total, chromosome 3A had the largest number of QTLs. In our research most of the repeatedly detected QTLs across environments were not significant.

\section{Conclusions}

The goal of crop genomics is to understand the genetic and molecular basis of all biological processes in plants that are relevant to the species (Vassilev et al., 2006). QTL mapping thus represents the foundation for the selection of markers for crop breeding. First, selection should be applied particularly for QTL with main genetic 
effects, which will likely show stable performance across different environments. In one hand, the actions of QTLs involved in epistatic interactions always depend on other loci. On the other hand, these QTLs could produce varieties adapted to specific ecosystems. Thus, it should be more efficient to select superior genetic combinations rather than selection of single genes. Second, selection programs should consider QTLs with interaction effects in different environments $(\mathrm{QE})$, which will also provide confidence for breeders prior to undertaking marker-assisted selection for complex traits in the design and implementation of breeding strategies. However, QE interaction effects might not be well applied across various environments. Third, selection programs should be based on closely linked or pleiotropic QTL. Breeders could possibly simultaneously improve several related traits by selecting such trait-correlated QTL (Liu et al., 2006). In the current study, closely linked or pleiotropic QTLs were not coincident with yield components, suggested that selection for a yield component could not efficiently increase grain yield. These results will make marker-assisted selection not effective for improvement of wheat yield and its compounds. Thus, detailed information on loci involved in related traits and their genetic relationships will not certainly be helpful to improve grain yield potential in our research.

\section{REFERENCE}

[1] Cooper, M., van Eeuwijk, F. A., Hammer, G. L., Podlich, D. W., Messina, C. (2009): Modeling QTL for complex traits: detection and context for plant breeding. - Current Opinion in Plant Biology 12: 231-240.

[2] Cuthbert, J. L., Somers, D. J., Brule-Babel, A. L., Brown, P. D., Crow, G. H. (2008): Molecular mapping of quantitative trait loci for yield and yield components in spring wheat (Triticum aestivum L.). - Theoretical and Applied Genetics 117: 595-608.

[3] Dixon, J. M. (2009): Wheat Facts and Futures 2009. - CIMMYT (International Maize and Wheat Improvement Center), El Batán.

[4] El-Feki, W. (2010): Mapping quantitative trait loci for bread making quality and agronomic traits in winter wheat under different soil moisture levels. - Ph.D. Dissertation, Colorado State University, USA.

[5] Emebiri, L., Michael, P., Moody, D. B., Ogbonnaya, F. C., Black C. (2009): Pyramiding QTLs to improve malting quality in barley: gains in phenotype and genetic diversity. Molecular Breeding 23: 219-228.

[6] George, M. L. C., Prasanna, B. M., Rathore, R. S., Setty, T. A. S., Kasim, F., Azrai, M., Vasal, S., Balla, O., Hautea, D., Canama, A., Regalado, E., Vargas, Khairallah, M., Jeffers, M. and Hoisingotn, D. (2003): Identification of QTLs conferring resistance to downy mildews of maize in Asia. - Theoretical and Applied Genetics 107: 544-551.

[7] Huang, X. Q., Cloutier, S., Lycar, L., Radovanovic, N. (2006): Molecular detection of QTLs for agronomic and quality traits in a doubled haploid population derived from two Canadian wheats (Triticum aestivum L.). - Theoretical and Applied Genetics 113: 753766.

[8] Hussain, S.S., Rivandi, A. (2007): Molecular breeding for drought tolerance in plants: wheat prospective. - Proceedings of the Pakistan Academy of Sciences 44(1): 35-62.

[9] Kirigwi, F. M., Van Ginkel M., Brown-Guedira G., Gill B. S., Paulsen G. M., Fritz A. K. (2007): Markers associated with a QTL for grain yield in wheat under drought. Molecular Breeding 20: 401-413.

[10] Korff, M., Wang. H., Le'on, J,. Pillen, K. (2008): AB-QTL analysis in spring barley: III. Identification of exotic alleles for the improvement of malting quality. - Molecular Breeding 21: 81-93. 
[11] Lapitan, N. L. V., Hess, A., Cooper, B., Botha, A., Badillo, D., Hari, I., Menert, J., Close, T., Wright, L., Hanning, G., Tahir, M., Lawrence, C. (2009): Differentially expressed genes during malting and correlation with malting quality phenotypes in barley (Hordeum vulgare L.). - Theoretical Applied Genetics 118: 937-952.

[12] Li, C., Bai, C., Chao, S., Carver, B., Wang, Z. (2016): Single nucleotide polymorphisms linked to quantitative trait loci for grain quality traits in wheat. - The crop journal 4:1-11.

[13] Li, X., Xia, X., Xiao, Y., He, Z., Wang, D., Trethowan, R., Wang, H., Chen, X. (2014): QTL mapping for plant height and yield components in common wheat under waterlimited and full irrigation environments. - Crop and Pasture Science 66(7): 660-670.

[14] Li, Z. K. (1998): Molecular Analysis of Epistasis Affecting Complex Traits. In: Paterson, A. H. (ed.) Molecular Dissection of Complex Traits. - CRC Press, Boca Raton.

[15] Liao, C. Y., Wu, P., Hu, B., Yi, K. K. (2001): Effects of genetic background and environment on QTLs and epistasis for rice (Oryza sativa L.) panicle number. Theoretical Applied Genetics 103: 104-111.

[16] Liu, G. F., Yang, J., Zhu, J. (2006): Mapping QTL for biomass yield and its components in rice (Oryza sativa L.). - Yi Chuan Xue Bao 33: 607-616.

[17] Marza, F., Bai, G. H., Carver, B. F., Zhou, W. C. (2006): Quantitative trait loci for yield and related traits in the wheat population Ning7840 x Clark. - Theoretical and Applied Genetics 112: 688-698.

[18] McIntyre, C. L., Mathews K. L., Rattey A., Chapman S. C., Drenth J., Ghaderi M., Reynolds M., Shorter R. (2010): Molecular detection of genomic regions associated with grain yield and yield-related components in an elite bread wheat cross evaluated under irrigated and rainfed conditions. - Theoretical and Applied Genetics 120: 527-541.

[19] Mergoum, M., Harilal, V. E., Simsek, S., Alamri, M. S., Schatz, B. G., Kianian, S. F., Elias, E., Kumar, A., Bassi F. M.(2013): Agronomic and quality QTL mapping in spring wheat. - Journal of Plant Breeding and Genetics 01: 19-33.

[20] Pinto, R. S., Reynolds, M. P., Mathews, K. L., McIntyre, C. L., Olivares-Villegas, J. J., Chapman S. C. (2010): Heat and drought adaptive QTL in a wheat population designed to minimize confounding agronomic effects. - Theoretical Applied Genetics 121: 10011021.

[21] Quarrie, S. A., Steed, A., Calestani, C., Semikhodskii, A. (2005): A high-density genetic map of hexaploid wheat (Triticum aestivum L.) from the cross Chinese Spring X SQ1 and its use to compare QTLs for grain yield across a range of environments. - Theoretical and Applied Genetics 110: 865-880.

[22] Rebetzke, G. J., Ellis, M. H., Bonnett, D. G., Mickelson, B., Condon, A. G., Richards, R. A. (2012): Height reduction and agronomic performance for selected gibberellinresponsive dwarfing genes in bread wheat (Triticum aestivum L.). - Field Crops Research 126: 87-96.

[23] Roder, M. S., Korzun, V., Wendehake, K., Plaschke, J., Tixier, M. H., Leroy, P., Ganal, M. (1998): A microsatellite map of wheat. - Genetics 149: 2007-2023.

[24] Roder, M. S., Plaschke, J., Konig, S. U., Borner, A., Sorrels, M. E.,. Tanksley, S. D., Ganal, M. W. (1995): Abundance, variability and chromosomal location of microsatellites in wheat. - Molecular and General Genetics 246: 327-333.

[25] Simmonds, J., Scott, P., Leverington-Waite, M., Turner, A. S, Brinton, J., Korzun, V., Snapel, J., Uauy, C. (2014): Identification and independent validation of a stable yield and thousand grain weight QTL on chromosome 6A of hexaploid wheat (Triticum aestivum L.). - BMC Plant Biology 14: 191-213.

[26] Slafer, G. A. (2003): Genetic basis of yield as viewed from a crop physiologist's perspective. - Annals of Applied Biology 21: 81-93.

[27] Tanksley, S. D. (1993): Molecular markers in plant breeding. - Plant Mol. Biol. Rep. 1: 3-8.

[28] Vassilev, D., Nenov, A., Atanassov, A., Dimov, G. (2006): Application of bioinformatics in fruit plant breeding. - J. Fruit Ornam. Plant Res. 14(Suppl 1): 145-162. 
[29] Wanjugi, H., Coleman-Derr, D., Huo, N., Anderson, O., Gu, Y. Q. (2009): Rapid development of PCR-based genome-specific repetitive DNA junction markers in wheat. Genome 52: 576-587.

[30] Wei, L., Li, J. M., Hou, X. J., Wang, X., Li, H. Q., Zhang, B., Chen, W. J., Liu, D., Liu, B. L., Zhang, H. G. (2014): QTL positioning of thousand wheat grain weight in Qaidam Basin. - Open Journal of Genetics 4: 239-244.

[31] Wu, X., Chang, X., Jing, R. (2012): Genetic insight into yield-associated traits of wheat grown in multiple rain-fed environments. - PLoS One 7(2): e31249. doi:10.1371/journal.pone.0031249.

[32] Zhang, H., Chen, J., Li, R., Deng, Z., Zhang, K., Liu, B., Tian, J. (2016): Conditional QTL mapping of three yield components in common wheat (Triticum aestivum L.). The Crop Journal 4: 220-228.

[33] Zhang, J., Chen, J., Chu, C., Zhao, W., Wheeler, J., Souza, E. J., Zemetra, R. S. (2014): Genetic dissection of QTL associated with grain yield in diverse environments. Agronomy 4: 556-578.

[34] Zhang, L. Y., Marchand, S., Tinker, N. A., Belzile, F. (2009): Population structure and linkage disequilibrium in barley assessed by DArT markers. - Theoretical and Applied Genetics 119:43-52.

[35] Zhuang, J. Y, Fan, Y. Y, Rao, Z. M., Wu, J. L. (2002): Analysis on additive effects and additive-by-additive epistatic effects of QTLs for yield traits in a recombinant inbred line population of rice. - Theoretical and Applied Genetics 105: 1137-1145. 